University of New Mexico

UNM Digital Repository

Mathematics and Statistics Faculty and Staff

Publications

Academic Department Resources

$8-2020$

\title{
A Review of Fuzzy Soft Topological Spaces, Intuitionistic Fuzzy Soft Topological Spaces and Neutrosophic Soft Topological Spaces
}

Florentin Smarandache

M. Parimala

M. Karthika

Follow this and additional works at: https://digitalrepository.unm.edu/math_fsp

Part of the Geometry and Topology Commons, Logic and Foundations Commons, Other Mathematics Commons, and the Set Theory Commons 


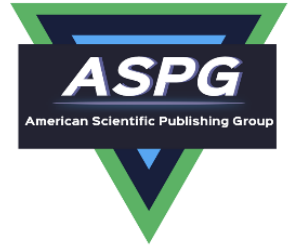

\title{
A Review of Fuzzy Soft Topological Spaces, Intuitionistic Fuzzy Soft Topological Spaces and Neutrosophic Soft Topological Spaces
}

\author{
${ }^{1}$ M. Parimala, ${ }^{2}$ M.Karthika, ${ }^{3}$ F. Smarandache \\ ${ }^{1,2}$ Department of Mathematics, Bannari Amman Institute of Technology, TN, India-638 401. \\ ${ }^{3}$ University of New Mexico, Gallup, NM 87301, USA \\ Email ${ }^{1}$ rishwanthpari@gmail.com, Email ${ }^{2}$ karthikamuthusamy1991@gmail.com, \\ Email $^{3}$ fsmarandache@gmail.com
}

\begin{abstract}
The notion of fuzzy sets initiated to overcome the uncertainty of an object. Fuzzy topological space, intuitionistic fuzzy sets in topological structure space, vagueness in topological structure space, rough sets in topological space, theory of hesitancy and neutrosophic topological space, etc. are the extension of fuzzy sets. Soft set is a family of parameters which is also a set. Fuzzy soft topological space, intuitionistic fuzzy soft and neutrosophic soft topological space are obtained by incorporating soft sets with various topological structures. This motivates to write a review and study on various soft set concepts. This paper shows the detailed review of soft topological spaces in various sets like fuzzy, Intuitionistic fuzzy set and neutrosophy. Eventually, we compared some of the existing tools in the literature for easy understanding and exhibited their advantages and limitations.
\end{abstract}

Keywords: Soft sets, fuzzy soft topological space, intuitionistic fuzzy soft topological space, neutrosophic soft topological space.

\section{Introduction}

In the year 1999, Molodtsov ${ }^{47}$ proposed the concept of soft sets (SS). This concept developed to overcome the difficulty to fix membership for each case. SS is a family of parameterization of the universe of discourse. Parameters may be numbers, meaningful words, sentences, etc. Anyone could define the parameterization for their convenient. This technique is very useful to model the uncertainties. Also, Molodtsov defined some basic operations and presented some uses of SS, such as stability and operations research, etc.

The first definition of soft spaces was introduced by the authors Shabir and $\mathrm{Naz}^{70}$ and it is defined on the universe of discourse with a fixed set of parameters. Also they proved that a soft topological space provides

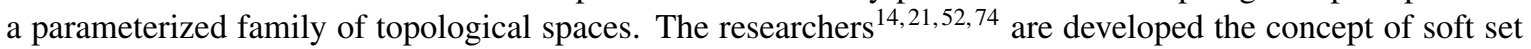
theory.

Fuzzy set (FS) was introduced by Zadeh ${ }^{81}$ in the year 1965, every element ' $a$ ' in A has a membership value, where $A$ is mapped from the universe of discourse to $[0,1]$. Later Chang 24 introduced the concept fuzzy topology in the literature, which satisfies the three axioms of topology and also Chang used the same notation in fuzzy topology as Zadeh used for FS. After few years, Lowen ${ }^{39}$ defined fuzzy topology which is different from definition by Chang. Maji et al ${ }^{[2]}$ proposed the concept of fuzzy soft set (FSS) and defined some basic operations. Later, Tanay et al ${ }^{72}$ introduced fuzzy soft topological space (FSTS)and established the basic definitions of FSTS by incorporating the fuzzy topology and soft set. FSTS was applied in various ways say, game theory, analysis, etc. Fuzzy soft set in topological space further studied by Roy! ${ }^{61,63}$ The authors $10,22[30,36,45[50,54$ are successfully applied FSTS in real life.

FS failed to address the rejection of an object in the set. So Atanasso $\frac{12}{12}$ proposed the theory where every object in a set has both acceptance and rejection with subject to the constraint that sum of acceptance and rejection should not exceed 1 and non-negative and that theory is called Intuitionistic fuzzy set theory. Intuitionistic fuzzy set A(a) is an generalization of fuzzy set where every element a in A is a subset of universal set have degree of membership and degree of non- membership and each function map from the universe of 
discourse to the interval $[0,1]$. Researchers developed the theory by generalising it and got new result through extension. ${ }^{6 / 15] 16] 57 / 59}$ Later, Maji et al ${ }^{[3]}$ introduced the notion of intuitionistic fuzzy soft set (IFSS). D. Coker $^{\sqrt{27}}$ initiated the concept of IFSTS and followed by $\sqrt{34533,76}$ developed the concept in decision making.

Atanassov failed to address the problem when indeterminacy occurs in the object. To address the difficulty, Smarandache $e^{6768}$ originated the concept called neutrosophic set. Every element in the neutrosophic set has truth, indeterminacy and falsity values respectively and which are maps from universe of discourse to $[0,1]$ with the constraint that truth, indeterminacy and falsity values should not exceed 3 and not less than zero under addition. Many complex problems in statistics, in graph theory when relationship between the object have acceptance, rejection and also indeterminacy, physics, image processing, networking and in decision making which can't be solved by existing classical methods. The generalisation of this notion also exist in the literature, namely neutrosophic soft topology, neutrosophic nano topology, neutrosophic nano ideals topology, neutrosophic support soft set, $\sqrt[56]{6}$ neutrosophic soft supra topological spaces in various sets, etc. Maji et al ${ }^{41}$ presented the concepts of neutrosophic soft set. Maji ${ }^{44}$ successfully applied the concept of neutrosophic soft sets (NSS) in pattern recognition, reasoning etc. Thereafter, Ber $2^{18 \mid 19}$ initiated the concept of neutrosophic

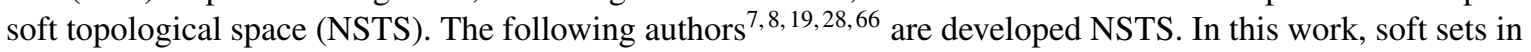
various topological spaces are studied in detail. Advantages and limitations of different soft topological spaces are presented. Eventually comparison table of classical soft topological space, FSTS, IFSTS, NSTS are also presented.

\section{Preliminaries}

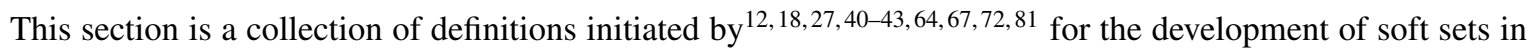
various uncertainty sets.

Definition 2.1. Fuzzy set $\mathrm{A}(\mathrm{a})$ of universal set $\mathrm{X}$ is defined by $A=\left\{\left(a, \mu_{A}(a)\right): a \in X\right\}$, where $\mu_{A}$ represent the degree of membership and it is mapped from the universal set $\mathrm{X}$ to the unit interval $[0,1]$.

Definition 2.2. The pair $(F, A)$ is called a FSS over $\mathrm{X}$, where the mapping $F: A \rightarrow F(U), \mathrm{F}(\mathrm{U})$ is the set of all fuzzy subsets of non-empty set $\mathrm{X}$ and $\mathrm{A}$ is a subset of the set of parameters $\mathrm{E}$.

Definition 2.3. Let the pair $(X, \tau)$ be a FSTS and $\tau$ be a family of FSS over $X \neq \emptyset$. The pair $(X, \tau)$ is said to be a FSTS if it satisfying the following conditions: (i) $0_{E}, 1_{E} \in \tau$. (ii) If $f_{A_{1}}, f_{A_{2}}$ in $\tau$, then $f_{A_{1}} \wedge f_{A_{2}}$ in $\tau$. (ii) If $\left(f_{A}\right)_{i}$ in $\tau$, for all $\mathrm{i}$ in $\mathbf{J}$, then union of $\left(f_{A}\right)_{i}$ in $\tau$. Then $\tau$ is called a topology of fuzzy soft sets on $X$.

Definition 2.4. Let $(X, \tau)$ be FSTS and $f_{A} \in F(X, E)$. The closure of fuzzy soft set $f_{A}$ is intersection of all fuzzy soft closed supersets of $f_{A}$.

Definition 2.5. Let $(X, \tau)$ be FSTS and $f_{A} \in F(X, E)$. The interior of fuzzy soft set $f_{A}$ is union of all fuzzy soft open subsets of $f_{A}$.

Definition 2.6. Intuitionistic fuzzy set $\mathrm{A}(\mathrm{a})$ on the non-empty set $\mathrm{X}$ is defined by $A=\left\{\left(a, \mu_{A}(a), \nu_{A}(a)\right)\right.$ : $a \in X\}$, where $\mu_{A}$ denotes truth value and $\nu_{A}$ denote the falsehood and the map of truth value and falsehood from the universal set $X$ to the interval $[0,1]$ and satisfying the constraint that sum of truth and falsehood value is lies between 0 and 1 , for each $a \in X$.

Definition 2.7. Let $\mathrm{X}$ and $\mathrm{E}$ be the initial universe and set of all parameters respectively and $\mathrm{A}$ is a subset of the parameter set $\mathrm{E}$. Let $\mathrm{IF}(\mathrm{U})$ be the set of all power set of $\mathrm{X}$. If the mapping $\mathrm{F}$ from the set A to $\operatorname{IF}(\mathrm{U})$, then the pair $(F, A)$ is said to be intuitionistic soft set over $\mathrm{X}$.

Definition 2.8. Neutrosophic set $\mathrm{A}$ (a) on the non-empty set $\mathrm{X}$ is defined by $A=\left\{\left(a, \mu_{A}(a), \sigma_{A}(a), \nu_{A}(a)\right)\right.$ : $a \in X\}$, where $\mu_{A}$ represent the degree of membership, $\sigma_{A}$ represent the degree of indeterminacy and $\nu_{A}$ represent the degree of non-membership and the map of membership, indeterminacy and non-membership from the universal set $\mathrm{X}$ to the interval $[0,1]$ and with the constraint $0 \leq \mu_{A}(a)+\sigma_{A}(a)+\nu_{A}(a) \leq 3$, for each $a \in X$.

Definition 2.9. Let $X$ be a non-empty set and the parameters set be $E$. The power set of $X$ is denoted by $P(X)$ and is defined as the collection of all neutrosophic set. The pair $(F, I)$ is called the NSS over X, where I is a subset of $\mathrm{X}$ and the map $\mathrm{F}$ from I to $\mathrm{P}(\mathrm{X})$.

Definition 2.10. Let $X$ and $\mathrm{E}$ are the non-empty set and set of parameters respectively and NSTS $(X, \tau)$ is a subset of NSS (X, E) satisfying the following:

(1) Null and universal soft set are the members of $\tau$. (2) Finite intersection of member of any finite sub collection of $\tau$ also in $\tau$. (3) Arbitrary union of member of any sub collection of $\tau$ also a member of $\tau$. 


\section{Soft Topological Spaces in Various Sets}

\subsection{Fuzzy soft set}

In $2008, \mathrm{Ya}^{\mathrm{78}}$ presented the concept of soft fuzzy set and this concept tested for the significance of existing soft fuzzy set. Lastly, FSS relations and soft fuzzy set relations are compared with some example. Cagman 23 modified the definition of FSS and studied the concept with some of its properties. Finally, fuzzy soft aggregation operator is defined for effective construction of decision process.

Generalized FSS introduced by Majumdar ${ }^{46}$ in 2010. Some properties of generalized FSS and its applications are presented by Manjumdar. Tanay ${ }^{72}$ first introduced the concept of FSTS to the literature. The authors also defined the notion of neighbourhood, family of neighborhood, interior and closure of FSS, Basis for FSTS and finally subspace of FSTS along with the some properties. Gunduz. $\mathrm{C}^{31}$ defined interior, closure of FSTS. Further, Gunduz introduced open and closed sets in respect of FSS and continuous mapping in FSS, homeomorphism of FSTS. Characteristics of fuzzy soft topological structure also discussed. In 2011, Zhi Kong et al ${ }^{[82}$ discussed FSS to present a real life problem with grey relation analysis theory. The result is verified with some cases. Mahant ${ }^{48}$ introduced and studied fuzzy soft point and its neighbourhood in a FSTS. Closure and interior of FSS are studied and investigated separation axioms and connectedness of FSTS. Abd El - Latif ${ }^{4}$ developed and studied the concept of pre-connected, pre-separated, pre-soft subspace of FSTS. Generally, Pre - disconnectedness of FSTS is not traditional property proved by Abd El - Latif ${ }^{[4}$ In 2012, Varo ${ }^{733}$ brought the notion of fuzzy soft continuity and projection mapping of FSTS. Simseklei ${ }^{67}$ defined fuzzy soft open sets and fuzzy soft closed sets in FSTS and also fuzzy Q-neighbourhood of fuzzy soft points are defined. Roy et al ${ }^{61 / 63}$ defined the concept of accumulation point using Q-neighbourhood and also proved that separation axioms exists using Q-neighbourhood in FSS.

Yang et al ${ }^{[7]}$ combined the concept of multi-fuzzy set and soft set to produce a new result called multifuzzy soft set. Also defined some theoretic operations say, union, intersection and complementary. Yang et al ${ }^{\text {[7] }}$ developed an algorithm using multi-fuzzy soft set. Eventually using the proposed algorithm, decision making problem is analysed. Roy and Maji ${ }^{62}$ analysed the decision making problems using fuzzy soft sets. They construct an algorithm for selecting object from universe of discourse by considering maximum value among the score using score function. Cetkin ${ }^{25}$ established the concept of continuous mappings in FSTS and presented the idea of anti-chain and isomorphism to FSTS.

In 2015, Kandi ${ }^{37}$ introduced the concept of semi connected set, semi s-connected set, semi separated set in FSTS. Sabir Hussain ${ }^{64}$ defined the soft pre-open set, soft alpha-open set in FSS and studied soft neighbourhood at fuzzy soft points. Also introduced soft regular open set and studied further. Finally, the relationships between the above proposed concepts are presented. Pre-open, pre-closed set of FSTS introduced by Abd ElLati ${ }^{1 / 3}$ and studied some properties of pre-regular, pre-normal space of FSTS. Fuzzy $\alpha$-connected set, fuzzy $\alpha$-separated set, fuzzy $\alpha$-S-connected set in FSTS established by A.M. Abd El-Latif. ${ }^{2}$

A. Kandil et al ${ }^{36}$ defined fuzzy soft point based on equivalence classes in the year 2015 and described that Universal fuzzy soft set can be written as the union of disjoint connected component. G. Kalpana et al ${ }^{35}$ introduced fuzzy soft r-open and fuzzy soft r-closed mappings, fuzzy soft r-closure, fuzzy soft r-interior, fuzzy soft r-continuous mapping through fuzzy soft set. Abd El-Latif ${ }^{3}$ initiated the notion of $\beta$-open soft sets and $\beta$-separation axioms in FSTS and established the properties of $\beta$-closure and $\beta$-regular, $\beta$-normal space in FSTS.

\subsection{Intuitionistic Fuzzy Soft Set}

Here, we present the initialization, extensions and generalization of intuitionistic fuzzy soft set in topological structure. Yang 976 originated the concept of interval - valued IFSS, defined the set theoretic operations and finally decision making problem solved by adopting existing algorithm. Mukherjee ${ }^{49}$ proposed and studied a new type of sequence of intuitionistic fuzzy soft multi sets and some of its properties are investigated. Also the increasing, decreasing and convergent sequences of intuitionistic fuzzy soft multi- topological spaces are introduced by Mukherjee ${ }^{49}$ Finally, cluster intuitionistic fuzzy soft multi topological space and their properties are studied. In 2010, $\mathrm{X} \mathrm{u}^{74}$ presented the concept of IFSS by merging K.Atanassov intuitionistic fuzzy set and soft set. Developed some basic operations and applying this tool to target the type recognition problem. Jiang et al ${ }^{[33}$ combined the two classical methods viz. soft set and interval-valued intuitionistic fuzzy set and produced a new result called interval-valued IFSS. Union, intersection and complement of interval-valued IFSS defined and established some basic properties.

In 2012 Yin et al ${ }^{79}$ introduced further the concept of IFSS. In particular, theoretical operations such as union, intersection and complement, etc. are introduced. Mapping on IFSS introduced and their basic properties also presented. Li et al. ${ }^{40}$ proposed the novel notion called IFSTS in the year 2013 . The author 
also defined the interior, closure, base, relative complement and absolute IFSS and IFSTS. Some properties of IFSTS also presented.

In 2013, Agarwal et al ${ }^{[5}$ developed the concept of generalized IFSS and this developed a generalized parameter to pool the intuitionistic fuzzy numbers. The author has developed three different algorithms mainly for decision making. One is for in medical diagnosis to compare the intuitionistic fuzzy numbers and remaining for measure the similarity, if any in selecting the supplier. Kumud Borgohain ${ }^{38}$ studied IFSTS and defined intuitionistic fuzzy soft separation axioms, normal space and finally completely normal space of IFSTS. Osmanoglu et al .55 introduced intuitionistic fuzzy soft finer and coarser topological space, Intuitionistic fuzzy soft discrete topology and intuitionistic fuzzy soft indiscrete topology. Further, soft points and complement of intuitionistic fuzzy soft points and separation axioms of the same introduced and their properties also studied. Cetkin ${ }^{26}$ introduced the definition of closure intuitionistic supra fuzzy soft topological space.

In 2014, Bayramov. $S^{13}$ introduced the basic definitions of IFSTS namely, null and absolute IFSTS, interior and closure, associated closure of IFSTS. Some basic properties also investigated. Mukherje ${ }^{51}$ established the notion of intuitionistic fuzzy soft multi topological space for the parameterized family and also established the basic structure of intuitionistic fuzzy soft multi topological structure.

Shuker Mahmood ${ }^{71}$ studied and established soft b-closed, soft b-continuous mapping, soft b- closed disconnectedness of IFSTS. In 2017, Yogalakshmi ${ }^{800}$ initiated the concept of various compactness of IFSTS, namely almost compact, nearly compact, etc and also studied intuitionistic soft fuzzy filter and intuitionistic soft fuzzy prime filter of IFSTS.

\subsection{Neutrosophic soft set}

This section contains the overview of various studies on NSS. In 2012, Maji ${ }^{41}$ defined the concept of NSS by combining soft set and neutrosophic set. Some basic operations of NSS, such as union, intersection and complement are defined and developed some properties of NSS. In the year 2013, Said Broumi20 presented the concept of generalized NSS with basic definitions and properties of generalized NSS. Deli ${ }^{29}$ defined the notion of relation on NSS. The composition of NSS is used to compose two different NSS. Deli29 examined the following concepts, namely equivalence relation, equivalence class and quotient of NSS. Deli also analyzed the decision making problem using NSS relation. Arockiarani 9 defined a distance measure and score function to present a decision making problem using the existing tool called NSS.

In 2017, Al-Quran ${ }^{11}$ introduced the notion of neutrosophic vague soft set which is an extended concept of classical soft set. Some basic operations and properties are defined and studied and at the end of the work, presented the decision making problem using the proposed concept to show the effectiveness. Parimala et al. $\frac{56}{5}$ introduced an algorithm to analyze the medical diagnosis problem using interval-valued FSTS. In their work, some basic theoretic operations are also investigated.

Bera ${ }^{\sqrt{18}}$ introduced the concept of NSTS. In the introduction paper, the authors are also defined interior, closure, base for NSTS, subspace of NSTS and regular NSTS. Finally some properties of NSTS and separation axioms with different characteristics are studied and investigated.

In 2018 Bera ${ }^{17}$ introduced neutrosophic soft connected and compact topological space along with some properties. Finally the concept of continuous mapping on NSTS introduced and studied. Gunduz Aras et al al ${ }^{[32}$ established the definition of NSS and introduced the neutrosophic soft point. Finally separation axioms and subspace of NSTS are studied in detail. Parimala et al.$^{60}$ proposed a new concept by incorporating NSS with hesitancy degree, which is exclusively for finding the residual of NSS.

\section{Advantages and Limitations}

Advantages and limitation of classical topological space and other topological spaces, such as FSTS, IFSTS, NSTS are presented here. 


\begin{tabular}{|c|c|c|}
\hline Types & Advantages & Limitations \\
\hline General topology & $\begin{array}{l}\text { It's a classical method and it is basic for } \\
\text { all other topological space. }\end{array}$ & $\begin{array}{l}\text { We could not apply the classical } \\
\text { approach for uncertainties and for } \\
\text { many real life fields. }\end{array}$ \\
\hline Fuzzy topology & $\begin{array}{l}\text { In fuzzy topology, every element has } \\
\text { membership grade which lies between }[0 \text {, } \\
\text { 1]. }\end{array}$ & $\begin{array}{l}\text { Rejection part of membership does } \\
\text { not exist in the fuzzy topology. }\end{array}$ \\
\hline $\begin{array}{l}\text { Intuitionistic fuzzy } \\
\text { topology }\end{array}$ & $\begin{array}{l}\text { Every element in the set has truth and } \\
\text { falsehood value. }\end{array}$ & $\begin{array}{l}\text { It's difficult to apply when some ele- } \\
\text { ment have indeterminacy or indeter- } \\
\text { minate form. }\end{array}$ \\
\hline $\begin{array}{l}\text { Neutrosophic topol- } \\
\text { ogy }\end{array}$ & $\begin{array}{l}\text { Every element in the non-empty set has } \\
\text { acceptance, rejection and indeterminacy } \\
\text { value. So all variables in the universe of } \\
\text { discourse have value between }[0,1] \text {. }\end{array}$ & $\begin{array}{l}\text { Residual part may lead to some ob- } \\
\text { vious errors in the solution. }\end{array}$ \\
\hline Fuzzy soft topology & $\begin{array}{l}\text { A non-empty set can be written as disjoint } \\
\text { union of parameters set. One can sepa- } \\
\text { rate the characteristic from the universal } \\
\text { set and investigate according to the need } \\
\text { of problem. }\end{array}$ & $\begin{array}{l}\text { Non-acceptance of an element in the } \\
\text { parameter does not consider. }\end{array}$ \\
\hline $\begin{array}{l}\text { Intuitionistic fuzzy } \\
\text { soft topology }\end{array}$ & $\begin{array}{l}\text { Every element in the parameterization has } \\
\text { possibility of acceptance and possibility } \\
\text { of non-acceptance value. }\end{array}$ & $\begin{array}{l}\text { Omitting the possibility of neutral- } \\
\text { ity. }\end{array}$ \\
\hline $\begin{array}{l}\text { Neutrosophic soft } \\
\text { topology }\end{array}$ & $\begin{array}{l}\text { Here we consider acceptance rate, non- } \\
\text { acceptance rate and neutrality rate of all } \\
\text { elements in the parameter. }\end{array}$ & $\begin{array}{l}\text { Accuracy may affect if the residual } \\
\text { rate is high. }\end{array}$ \\
\hline
\end{tabular}

The following table emphasize the comparison of various tools which we discussed in this overview.

\begin{tabular}{|c|c|c|c|c|c|c|}
\hline Sets & Image & Pre-Image & Uncertainty & $\begin{array}{l}\text { Truth } \\
\text { Value of } \\
\text { Parame- } \\
\text { ter }\end{array}$ & $\begin{array}{l}\text { False } \\
\text { value of } \\
\text { Parame- } \\
\text { ter }\end{array}$ & $\begin{array}{l}\text { Indeterminacy } \\
\text { of parameter. }\end{array}$ \\
\hline Classical sets & $\begin{array}{l}\text { Universal } \\
\text { set }\end{array}$ & Integer Set. & - & - & - & - \\
\hline Soft Topology & $\begin{array}{l}\text { Initial } \\
\text { Universe }\end{array}$ & $\begin{array}{l}\text { Power set whose } \\
\text { ranges } \quad \text { from } \\
\text { closed interval } 0 \\
\text { to } 1\end{array}$ & - & - & - & - \\
\hline $\begin{array}{l}\text { Fuzzy Soft } \\
\text { Topology }\end{array}$ & $\begin{array}{l}\text { Initial } \\
\text { Universe }\end{array}$ & $\begin{array}{l}\text { Power set whose } \\
\text { ranges from } \\
\text { closed interval } 0 \\
\text { to } 1\end{array}$ & Present & Present & - & - \\
\hline $\begin{array}{l}\text { Intuitionistic } \\
\text { Soft Topolog- } \\
\text { ical Space }\end{array}$ & $\begin{array}{l}\text { Initial } \\
\text { Universe }\end{array}$ & $\begin{array}{l}\text { Power set whose } \\
\text { ranges from } \\
\text { closed interval } 0 \\
\text { to } 1\end{array}$ & Present & Present & Present & - \\
\hline $\begin{array}{l}\text { Neutrosophic } \\
\text { soft topologi- } \\
\text { cal space }\end{array}$ & $\begin{array}{l}\text { Initial } \\
\text { Universe }\end{array}$ & $\begin{array}{l}\text { Power set whose } \\
\text { ranges from } \\
\text { closed interval } 0 \\
\text { to } 1\end{array}$ & Present & Present & Present & present \\
\hline
\end{tabular}

\section{Conclusions}

Topological space has several applications in mathematics and in other fields like operations research, physics, data science, etc. But sometimes applying the concept of topology for real life application is difficult, because of uncertainties, inconsistent, incomplete information of the element. Fuzzy soft topological space introduced to overcome the difficulty in classical set which deals uncertainty of the object and intuitionistic fuzzy soft topological space established to solve some problem which encounter in fuzzy soft topology. Some cases, 
object has indeterminacy value, for those cases the previous tools can't be used. So Neutrosophic set has been introduced to deal the uncertainty, incomplete and inconsistent. This paper is thorough study of all these tools. Advantages and limitations of all existing tools are discussed.

\section{References}

[1] Abd El-Latif, A. M., Characterizations of fuzzy soft pre separation axioms, Journal of New Theory, 7, pp. 47-63, 2015.

[2] Abd El-latif, A. M., Fuzzy soft $\alpha$-connectedness in fuzzy soft topological spaces, Math.Sci. Lett., 5 (1), pp. 85-91,2016.

[3] Abd El-latif, A. M., Fuzzy soft separation axioms based on fuzzy $\beta$-open soft sets, Ann. Fuzzy Math. Inform., 11 (2), pp. 223-239,2016.

[4] Abd El-latif, A. M., Hosny, R. A., Fuzzy soft pre-connected properties in fuzzy soft topological spaces, South Asian J Math, 5 (5), pp. 202-213, 2015.

[5] Agarwal, M., Biswas, K. K. and Henmandlu, M., Generalised intuitionistic fuzzy soft sets with application in decision making, Applied Soft Computing, 13, pp. 3552-3566,2013.

[6] Amit Kumar Singh., Rekha Srivastava, Separation axioms in intuitionistic fuzzy topological spaces, Hindawi Publishing Corporation Advances in Fuzzy Systems, Article ID 604396, pp. 1-7,2012.

[7] Arockiarani. I., Martina Jency. J., More on fuzzy neutrosophic sets and fuzzy neutrosophic topological spaces, Inter.J. Innov. Research \& Studies, 3 (5), 643-652,2014.

[8] Arockiarani, I., Sumathi, I. R. and Martina Jency, J., Fuzzy neutrosophic soft topological spaces, Inter.J.Math.Archive, 4 (10), pp. 225-238,2013.

[9] Arockiarani. I., A Fuzzy neutrosophic soft set model in medical diagnosis, in:IEEE conference on Norbert Wiener in the 21st Century, (2014), Boston, MA, USA.

[10] Aygunoglu, A., Cetkin, V., Aygun, H., An introduction to fuzzy soft topological spaces, Hacettepe Journal of Mathematics and Statistics, 43 (2) ,pp. 197 - 208, 2014.

[11] Al-Quran, A., Hassan, N., Neutrosophic vague soft set and its application, Malaysian Journal of Mathematical Science, 11 (2), pp. 141-163,2017.

[12] Atanassov, K., Intuitionistic fuzzy sets, Fuzzy Sets and Syst., 20, pp. 87-96,1986.

[13] Bayramov, S., Gunduz, C., On intuitionistic fuzzy soft topological spaces, TWMS. J. Pure Appl. Math., 5, pp. 66-79,2014.

[14] Bayramov, S., Gunduz, C., A New approach to separability and compactness in soft topological spaces. TWMS J. Pure Appl. Math., 9, pp. 82-93,2018.

[15] Bayramov,S. and Gunduz, G., On intuitionistic fuzzy soft topological spaces, Inter.J.PureAppl.Math, 5(1), pp. 66-79,2014.

[16] Bora,M., Neog, T. J., Sut,D.K., Some new operations of intuitionistic fuzzy soft sets, International Journals of Soft Computing and Engineering, 2(4), pp.2231-2307,2012.

[17] Bera, T., Mahapatra, N. K., On neutrosophic soft topological space, Neutrosophic Sets and Systems, 19, pp. 3- 15,2018.

[18] Bera, T., Mahapatra, N.K., Introduction to neutrosophic soft topological space, OPSEARCH, 54(4),pp. 841-867,2017.

[19] Broumi, S., and Smarandache, F., Intuitionistic neutrosophic soft set, Journal of Information and Computing Science, 8 (2), pp. 130-140,2013.

[20] Broumi, S., Generalized neutrosophic soft set, IJCSEIT,3 (2), pp. 17-30,2013. 
[21] Cagman, N., Karatas, S., Enginoglu, S., Soft topology, Computer and Mathematics with Application, 62, pp. 351-358,2011.

[22] Cagman, N., Citak, F. and Enginoglu, S., Fuzzy parameterized fuzzy soft set theory and its applications, Turkish Journal of Fuzzy Systems, 1 (1), pp. 21-35,2010.

[23] Cagman, N., Enginoglu, S., Citak,F., Fuzzy soft set theory and its application, Iranian Journal of fuzzy systems,8 (3), pp. 137-147,2011.

[24] Chang, C. L., Fuzzy topological spaces, J. Math. Anal. Appl., 24, pp.182-190,1968.

[25] Cetkin, V., Aygun, H., A Note on fuzzy soft topological spaces, Conference of the European Society for Fuzzy Logic and Technology,2013.

[26] Cetkin, V., Aygun, H., A Note on intuitionistic supra fuzzy soft topological spaces, Notes on Intuitionistic Fuzzy Sets, 21 (4), pp. 48-57,2015.

[27] Coker, D., An Introduction to intuitionistic fuzzy topological space, Fuzzy Sets and Systems, 88, pp. 81-89,1997.

[28] Deli, I., npn-Soft sets theory and applications, Annals of Fuzzy Mathematics and Informatics, 10 (6), pp. 847 -862,2015.

[29] Deli, I., Broumi, S., Neutrosophic soft relations and some properties, Annals of Fuzzy Mathematics and Informatics, 9 (1), pp. 169-182,2015.

[30] Dey, A., Pal, M., Generalised multi-fuzzy soft set and its application in decision making, Pacific Science Review A: Natural Science and Engineering, 17, pp. 23-28,2015.

[31] Gunduz Aras, C., Bayramov, S., Some results on fuzzy soft topological spaces, Math. Prob. in Engg., 20, pp. 1-10,2013.

[32] Gunduz Aras, C., Bayramov, S., Separation axioms on neutrosophic soft topological spaces, Turk J Math, 43 , pp. $498-510,2019$.

[33] Jiang, J., Tang,Y., Chen,Q., Li, H., Tang,J., Interval-valued intuitionistic fuzzy soft sets and their properties, Computer and Mathematics with Application, 60, pp. 906-918,2010.

[34] Lu,J., Pan,L., Yang,Y., A Group medical diagnosis model based on intuitionistic fuzzy soft sets, Applied soft computing Journal, 77, pp. 453-466,2017.

[35] Kalpana, G., Kalaivani, C., Fuzzy soft topology, International Journal of Engineering Studies,9 (1), pp. 45-56,2017.

[36] Kandil, A., Tantawy,O. A. E., El-Sheikh, S. A., Abd El-latif, A. M. and El-Sayed. S., Fuzzy soft $\alpha-$ connectedness in fuzzy soft topological spaces, Journal of Mathematics and Computer Applications Research, 2 (1), pp. 37-46,2015.

[37] Kandil, A., Tantawy,O. A. E., El-Sheikh, S. A., Abd El-latif, A. M., Fuzzy soft semi connected properties in fuzzy soft topological spaces, Math. Sci. Lett., 4, pp. 171-179,2015.

[38] Kumud Borgohain., Separation axioms in intuitionistic fuzzy soft topological space, International Journal of Mathematics Trends and Technology, 5, pp. 176-180,2014.

[39] Lowen, R., Fuzzy topological spaces and fuzzy compactness, J. Math. Anal. Appl. 56, pp. 621-633,1976.

[40] Li, Z., Cui, R., On the topological structure of intuitionistic fuzzy soft sets, Annals of Fuzzy Mathematics and Informatics, 5 (1), pp. 229-239,2013.

[41] Maji, P. K., Neutrosophic soft set, Annals of Fuzzy Mathematics and Informatics, 5, pp. 157-168,2013.

[42] Maji,P.K., Biswas, R., Roy, A. R., Fuzzy soft sets, Journal of Fuzzy Mathematics, 9 (3), pp. 589602,2001 .

[43] Maji,P.K., Biswas,R., Roy, A. R., Intuitionistic fuzzy soft sets, Journal of Fuzzy Mathematics, 9 (3), pp. 677-691,2001. 
[44] Maji,P.K., An application of weighted neutrosophic soft sets in a decision making problem, Springer proceedings in Mathematics and Statistics, 125, pp. 215-223,2015.

[45] Mahanta, J., Das, P. K., Results on fuzzy soft topological spaces, arXiv:1203.0634v1,2012.

[46] Majumdar, P., Samanta, S.K., Generalised fuzzy soft sets, Computers and Mathematics with Application, 59, pp. 1425-1432,2010.

[47] Molodtsov, D., Soft set theory-first results, Computers and Mathematics with Application, 37, pp. 1931,1999 .

[48] Mahanta, J., Das, P. K., Fuzzy soft topological spaces, Journal of Intelligent \& Fuzzy Systems, 32, pp.443-450,2017.

[49] Mukherjee, A., Das,A. K., Saha, A., Sequence in intuitionistic fuzzy soft multi topological spaces, NTMSCI, 3( 3), pp. 184-191,2015 .

[50] Mukherjee, A., Das,A. K., Topological structure formed by fuzzy soft multi sets, Bulletin of Cal. Math. Soc., 21, pp. 193-212,2013.

[51] Mukherjee, A., Das,A. K., Parameterized topological space induced by an intuitionistic fuzzy soft multi topological space, Annals of Pure and Applied Math., 7 pp. 7-12,2014.

[52] Mukherjee, A., Das, A. K. and Saha, A., Topological structure formed by soft multi sets and soft multi compact space, Annals of Fuzzy Mathematics and Informatics, 7, pp. 919-933,2014.

[53] Muthukumar,P., Sai sundara Krishnan, G., A similarity measure of intuitionistic fuzzy soft sets and its application in medical diagnosis, Applied Soft Computing, 41, pp. 148- 156,2016.

[54] Neog, T., Su, D. K., Hazarika, G. C., Fuzzy soft topological spaces, Inter J. Latest Trend Math., 2(1), pp. $87-96,2012$.

[55] Osmanoglu, I., Tokat, D., On intuitionistic fuzzy soft topology ,Gen. Math. Notes, 19 (2), pp. 59-70,2013.

[56] Parimala, M., Karthika, M., Jafari, S., Smarandache, F. and Udhayakumar, R., Decision- making via neutrosophic support soft topological spaces, Symmetry, 217(10), pp. 1-10,2018.

[57] Parimala, M., Karthika, M., Dhavaseelan, R. and Jafari, S., On neutrosophic supra pre- continuous functions in neutrosophic topological spaces, New Trends in Neutrosophic Theory and Applications, 2, pp. 371-383,2017.

[58] Parimala, M., Indirani, C., Perumal, R., On intuitionistic fuzzy contra psi-continuous mappings in topological spaces, International Journal of Pure and Applied Mathematics, 113 (12), pp. 107-114,2017.

[59] Parimala, M., Indirani, C., On intuitionistic fuzzy beta-supra open set and intuitionistic fuzzy beta-supra continuous functions, Notes on Intuitionistic Fuzzy Sets, 20 (3), pp. 6-12,2014.

[60] Parimala, M., Karthika, M,, Smarandache, F., Broumi,S., On $\alpha \omega$-closed sets and its connectedness in terms of neutrosophic topological spaces, International Journal of Neutrosophic Science, 2(2), PP: 82-88, 2020.

[61] Roy, S., Samanta, T. K., A Note on fuzzy soft topological spaces, Annals of fuzzy mathematics and informatics, 3(2), pp. 305-311,2012.

[62] Roy, A. R., Maji, P. K., A Fuzzy soft set theoretic approach to decision making problems, Journal of Computational and Applied Mathematics, 203, pp. 412-418,2007.

[63] Roy, S., Samanta, T. K., An introduction to open and closed sets on fuzzy soft topological spaces, Annals of Fuzzy Mathematics and Informatics, 6 (2), pp. 425- 431,2012.

[64] Sabir Hussain., On weak and strong forms of fuzzy soft open sets, Fuzzy information and Engineering, 8 (4), pp. 451-463,2016.

[65] Salama, A.A., Alblowi, S.A.,Neutrosophic set and neutrosophic topological spaces, IOSRJ.Mathematics, 3 (4), pp. 31-35,2012. 
[66] Sahin, M., Alkhazaleh,S., Ulucay,V., Neutrosophic soft expert sets, Applied Mathematics, 6, pp. 116127,2015 .

[67] Simsekler, T., Yuksel, S., Fuzzy soft topological space, Annals of fuzzy mathematics and Informatics, 5 (1), pp. 87-96,2013.

[68] Smarandache. F, Neutrosophy and neutrosophic logic, First International Conference on Neutrosophy, Neutrosophic Logic, Set, Probability and Statistics, University of New Mexico, Gallup, NM 87301, USA (2002).

[69] Smarandache, F., Neutrosophic set, a generalization of the intuitionistic fuzzy sets, Inter.J.Pure Appl.Math., 24, pp.287 - 297,2005.

[70] Shabir, M., Naz, M., On soft topological spaces, Comput. Math. Appl., 61, pp. 1786-1799,2011.

[71] Shuker Mahmood Khalil., On intuitionistic fuzzy soft $\beta$-closed sets in intuitionistic fuzzy soft topological spaces, Annals of Fuzzy Mathematics and Informatics, 10 (2), pp. 221-233,2015.

[72] Tanay, B., Burc Kandemir, M., Topological structure of fuzzy soft sets, Comp. Math. Appl., 61,pp. 2952$2957,2011$.

[73] Varol, B. P., Aygun, H., Fuzzy soft topology, Hacettepe Journal of Mathematics and Statistics, 41 (3), pp. $407-419,2012$.

[74] Xu, Y., Sun, Y., Li. D., Intuitionistic fuzzy soft set, 2nd International workshop on intelligent systems and applications, IEEE, China,2010.

[75] Yang, C., A note on soft set theory, Computers and Mathematics with Applications, 56, pp. 1899-1900,2008.

[76] Yang, X., Lin, T. S., Yang, J., Li, Y. and Yu, D., Combination of interval-valued fuzzy set and soft set, Computers and Mathematics with Applications 58 , pp. 521-527,2009.

[77] Yang. Y., Tan, X. and Meng, C., The multi-fuzzy soft set and its application in decision making, Applied Mathematical Modelling, 37, pp. 4915-4923,2013.

[78] Yao, B. X., Liu, J. L., Yan, R. X., Fuzzy soft set and soft fuzzy set, Fourth international conference on natural computation, IEEE.2008

[79] Yin, Y., Li, H. and Jun, Y. B., On algebraic structure of intuitionistic fuzzy soft sets, Computer and Mathematics with Applications, 64, pp. 2896-2911,2012.

[80] Yogalakshmi, T., On intuitionistic soft fuzzy compactness, International Journal of Pure and Applied Mathematics, 115 (9), pp. 231-237,2017.

[81] Zadeh, L.A.,Fuzzy sets, Information and Control, 8, pp.338-353,1965.

[82] Zhi Kong., Lifu Wang., Zhaoxia Wu., Application of fuzzy soft set in decision making problems based on grey theory, journal of Computational and applied Mathematics, 236, pp.1521-1530,2011. 